\title{
Gradient Structure-Phase State Formed at Thermomechanical Strengthening of 09G2S Steel
}

\author{
Victor E. Gromov, Yurii F. Ivanov, Vadim B. Kosterev, Sergey V. Konovalov, and Irina A. \\ Komissarova
}

\begin{abstract}
Evolution of phase state and defective substructure double-T iron made of 09G2S steel executed methods of transmission electron microscopy after thermo-mechanical strengthening. It is found out that as accelerated refrigeration approaches the surface gradient structure is formed in the material which is characterizes by regular parametric variation of dislocation substructure and midsized particles of cementite. Midsized particles of cementite and $\alpha$-phase fragments in the coating surface of the double- $T$ iron correspond to nanostructural condition.
\end{abstract}

Index Terms-Steel, structure, phase, thermo-mechanical strengthening.

\section{INTRODUCTION}

Purposeful operation of service properties of rolled metal and development of optimal mode of its strengthening must base upon knowledge about processes of structure formation under different technological influences. The most effective method of control of structure-phase state while producing armature and - structural shape is thermo-mechanical strengthening [1]-[6]. Accelerated refrigerating of rolling mill production line is one of the strengthening methods.

For realization of accelerated refrigerating technology at JSC West Siberian Metallurgical Plant the installation has been developed and assembled, in which finished feeds after exiting the finishing stand of mill 450 cooled along the structural sections according to the scheme Fig. 1. Temperature and speed parameters of rolling and accelerated refrigeration for different technologic variants are given in the Table I.

The preliminary accomplished researches of the produce mechanical properties have shown that after accelerated refrigeration at the mode P1 (without the accelerated refrigeration) strength properties of the double- $\mathrm{T}$ iron are below requirements of class 345 , that can be explained by ruggedness of the current element. After cooling at modes P2 and $\mathrm{P} 3$ properties became similar and better in comparison with the samples cooled at mode P4.

Manuscript received November 25, 2012; revised March 3, 2013. This work was supported by the RFBR grant (project No11-02-91150-GFEN_a) and the Ministry of education and science of Russia, project No 14.V37.21.0071, 14.V37.21.1166).

V. E. Gromov, S. V. Konovalov, I. A. Komissarova are with the Siberian State Industrial University, Novokuznetsk, Russia (e-mail: gromov@physics.sibsiu.ru).

Yu. F. Ivanov is with the Institute of High Current Electronics SB RAS Tonsk, Russia (e-mail: yufi@mail2000.ru).

V. B. Kosterev is with the JSC "EVRAZ-ZSMK", Novokuznetsk, Russia (e-mail: Kosterev_VB@zsmk.ru).

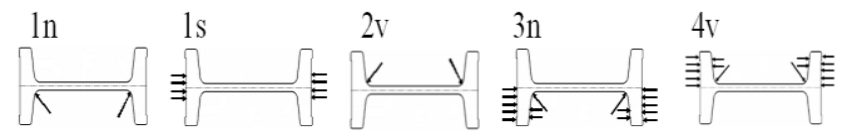

Fig. 1. The scheme double-T iron cooling DP155 along the structural sections

The purpose of the present work is a detection of regularities of phase-structure composition and defective substructure of double- $\mathrm{T}$ iron depending on the distance to surface of compulsory cooling.

TABLE I: MODES OF ROLLED METAL ACCELERATED REFRIGERATION

\begin{tabular}{|c|c|c|c|c|c|c|c|c|c|}
\hline \multirow{3}{*}{$\begin{array}{l}\text { No } \\
\bmod \\
\mathrm{e}\end{array}$} & \multirow{3}{*}{$\begin{array}{l}\mathrm{V}, \\
\mathrm{m} / \mathrm{s}\end{array}$} & \multirow{2}{*}{\multicolumn{3}{|c|}{$\mathrm{T},{ }^{\circ} \mathrm{C}$}} & \multicolumn{5}{|c|}{$\begin{array}{l}\text { Water supply pressure, } \\
\text { atm }\end{array}$} \\
\hline & & & & & \multicolumn{2}{|c|}{$\mathrm{I}$} & \multicolumn{2}{|c|}{ II } & \multirow[b]{2}{*}{$1 \mathrm{~s}$} \\
\hline & & $\begin{array}{c}\text { after } \\
\text { 3rd } \\
\text { stand }\end{array}$ & $\begin{array}{c}\text { after } \\
\text { 9rd } \\
\text { stand }\end{array}$ & $\begin{array}{l}\text { At entry in } \\
\text { refrigerator }\end{array}$ & $1 \mathrm{n}$ & $2 v$ & $3 n$ & $4 v$ & \\
\hline P1 & $\begin{array}{l}5 . \\
2\end{array}$ & $\begin{array}{c}1100- \\
1150\end{array}$ & $\begin{array}{c}1050 \\
- \\
1080\end{array}$ & $950-970$ & - & - & - & - & - \\
\hline $\mathrm{P} 2$ & $\begin{array}{l}5 . \\
2\end{array}$ & $\begin{array}{c}1050- \\
1150\end{array}$ & $\begin{array}{c}1040 \\
- \\
1080\end{array}$ & $720-770$ & 1.5 & 1.5 & 2.5 & 2.5 & 3.0 \\
\hline P3 & $\begin{array}{c}4 . \\
5\end{array}$ & $\begin{array}{c}1050- \\
1150\end{array}$ & $\begin{array}{c}1040 \\
- \\
1080\end{array}$ & $690-730$ & 1.5 & 1.5 & 2.5 & 2.5 & 3.5 \\
\hline P4 & $\begin{array}{l}6 . \\
0\end{array}$ & $\begin{array}{c}1050- \\
1160\end{array}$ & $\begin{array}{c}1060 \\
- \\
1100\end{array}$ & $800-850$ & 1.5 & 1.5 & 2.5 & 2.5 & 3.0 \\
\hline
\end{tabular}

\section{MAterial AND ReSEARCH TeChNiQue}

As a research material rolled blank with section $150 \times 200$ $\mathrm{mm}$ from steel $09 \mathrm{G} 2 \mathrm{~S}$ was used, its chemical composition is (mass.\%) $\quad 0.095 \% \mathrm{C}, \quad 0.66 \% \mathrm{Si}, \quad 1.56 \% \mathrm{Mn}, \quad 0.019 \% \mathrm{~S}$, $0.015 \% \mathrm{P}, 0.0057 \% \mathrm{~N}$.

According to the results of mechanical tests as research objects double- $\mathrm{T}$ iron was used and processed at mode P3. Structure and phase composition investigations of steel were carried out by methods of transmission electron microscopy of thin foils [7], [8]. To perform researches samples of $10 \mathrm{~mm}$ were selected from the forward leading ends of rolls. Plates of $0.3 \ldots 0.4 \mathrm{~mm}$ thickness were cut out from segment No 1 (Fig. 2) parallel to the inner surface of double-T shape (Fig. $3)$.

The cut out plates were located at a distance of 4 and $7 \mathrm{~mm}$ from the cooling surface (Fig. 3, layers 2 and 3). Besides, the layer structure was analyzed which is directly connected to the surface of cooling (Fig. 3, a layer 1), and the layer located in the center of preparation (Fig. 3). 


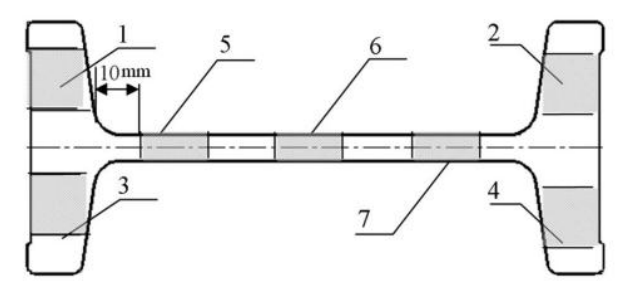

Fig. 2. The scheme segmentation of material blank for realization of the following mechanical test

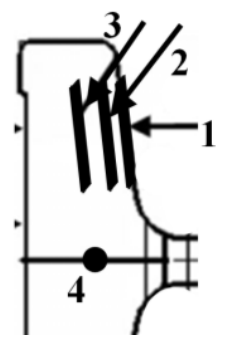

Fig. 3. The dissection scheme of the sample in the process of foils preparation for TEM analysis.

\section{RESUlTS OF RESEARCH AND DISCUSSION}

The analysis of phase composition and defective substructure of steel layers given in Fig. 3 and executed by the methods of transmission electron microscopy, has shown that regardless of the distance to the cooling surface there are two phases in the steel: $\alpha$-phase (solid solution with body-centered cubic lattice iron) and ferric carbide (cementite).

$\alpha$-phase ( $\alpha$-iron), the basic phase of the investigated steel, is in grains free from cementite particles (Fig. 4 a); grains which contain cementite particles of various morphology and sizes in their volume (Fig. 4, b). Besides, $\alpha$-phase is a perlite structural element of lamellar morphology (Fig. 4, c). According to it cementite forms structure of lamellar perlite and is located in the form of particles in the grains and on the boundary of ferrite grains.

Thermostrengthening of the 09G2S steel of the H-beam performed on the device of accelerated cooling according to regimes $\mathrm{P} 1$ and $\mathrm{P} 2$, leads to the formation of a multilayer (surface, transitional and central layers) of the microstructure of the H-beam profile. The structure of the stele in the transition layer and the central zone of the shelve under these cooling conditions resulted from the transformation according to diffusion mechanism, and consists of ferrite, perlite,

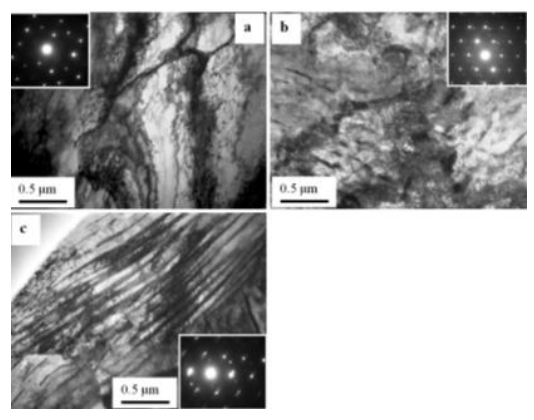

Fig. 4. The structure-phase condition of 09G2S steel after exiting from finishing stand mill 450 JCS West-Siberian metallurgical plant and accelerated refrigeration. a "degenerate" pearlite and carbide precipitates along the ferrite grain boundaries. The structure of the surface layer is formed as a result of the intermediate (regime P2) and shear (regime P1) mechanisms of $\gamma \Rightarrow \alpha$ transformation, followed by "self-tempering" process. Quantitative characteristics of the surface (hardened) layer, reflecting the most significant effect of hardening regime on the substructure of steel and identified according to the results of electron microscopic studies are presented in Table II.

Regardless of the distance to the cooling surface in the volume of $\alpha$-phase grains a high density of defects of various types is observed. Firstly, dislocations located chaotically or forming a waffle-type substructure; secondly, subboundaries and, thirdly, high angle boundaries. Also the ferrite component of perlite grains is defective - chaotic dislocation substructure and grids are observed.

Gradient of steel condition is found both at the level of structure-phase condition and at the level of defective substructure. The quantitative laws characterizing gradient character of the organization of structure phase condition of double- $T$ iron structure, subjected to compulsory water cooling, are presented in Fig. 5 and Fig. 6. The results analysis presented in the figures reveals the gradient character of the structure formed in the double- $\mathrm{T}$ iron from 09G2S steel as a result of rolling at mill 450 JSC West Siberian Metallurgical Plant and the accelerated cooling. It can be seen that as approaching the cooling surface the scalar density of the dispositions in the grains of ferrite (Fig. 5, curve 2) increases and ferrite interlayers of perlite grains (Fig. 5, curve 1), mean sizes of ferrite fragments (Fig. 6, curve 1) and the sizes of cementite particles (Fig. 6, curve 2) decrease.

It can be seen that in the surface layer of H-beam the state is formed, which based on the average size of fragments of $\alpha$-phase and cementite particles can be regarded as a nanostructure.

Analysis of the results presented above gives us grounds to conclude that the formation of nanoscale phase in the studied steel under thermomechanical processing and subsequent accelerated cooling of rolled products is possible with the implementation of such a processes. First, by dispersing of pearlite cementite plates colonies by cutting them by moving dislocations. Secondly, in the process of dissolution of pearlite colonies cementite plates and repeated

TABLE II: QUANTITATIVE CHARACTERISTICS OF THE STRUCTURE OF THE 09G2S STEEL HARDENED LAYER

\begin{tabular}{|c|c|c|c|c|c|c|c|c|}
\hline \multirow[b]{2}{*}{$\begin{array}{c}\text { Process } \\
\text { mode }\end{array}$} & \multicolumn{8}{|c|}{ The parameters of the structure } \\
\hline & $\Delta \mathrm{V}_{1}$ & $\begin{array}{l}\mathrm{d}_{1}, \\
\mu \mathrm{m}\end{array}$ & $\begin{array}{c}\rho_{1} \\
10^{10} \\
\mathrm{~cm}^{-2}\end{array}$ & $\Delta \mathrm{V}_{2}$ & $\begin{array}{r}\mathrm{d}_{2}, \\
\mu \mathrm{m}\end{array}$ & $\begin{array}{c}\rho_{2} \\
10^{10} \\
\mathrm{~cm}^{-2}\end{array}$ & $\begin{array}{l}\langle\rho\rangle, \\
10^{10} \\
\mathrm{~cm}^{-2}\end{array}$ & $\begin{array}{c}<\mathrm{d}>, \\
\mu \mathrm{m}\end{array}$ \\
\hline $\mathrm{P} 1$ & 0.9 & 0.2 & 5.0 & 0.1 & 0.5 & 2.8 & 4.78 & 0.23 \\
\hline $\mathrm{P} 2$ & 0.6 & 0.3 & 4.8 & 0.4 & 0.5 & 3.6 & 3.84 & 0.38 \\
\hline
\end{tabular}

Note: $\Delta \mathrm{V}_{1}, \Delta \mathrm{V}_{2}$ - the volume fraction of lamellar (martensite or bainite) and subgrain type, respectively; $\mathrm{d}_{1}, \mathrm{~d}_{2}$ - the average transverse sizes of plates and subgrains, respectively; $\rho_{1}, \rho_{2}$ - the scalar density of dislocations arranged in plates and subgrains, respectively; $\langle\rho\rangle-$ the average scalar density of dislocations in the layer (taking into account the types of structures); $\langle\mathrm{d}\rangle-$ the average size of the 
substructure in the layer (taking into account the types of structures).

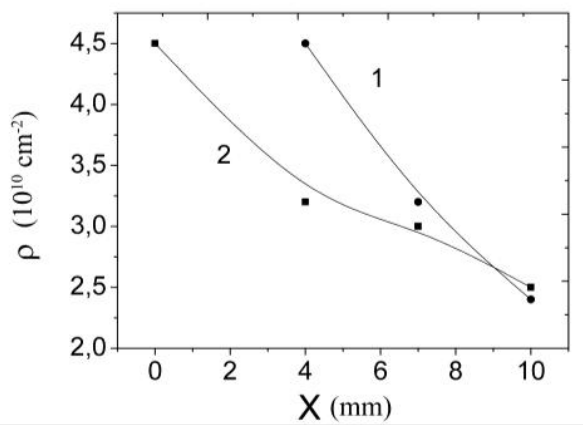

Fig. 5. Dependence from distance to the surface of the processed scalar density dislocations located in the ferrite part of perlite grains (curve 1) and ferrite grains (curve 2).

Precipitation of cementite particles on the dislocations, the boundaries of blocks, subgrains and grains. Third, during the decay of solid solution of carbon in the $\alpha$-iron, formed under the conditions of accelerated cooling of the steel ("self-tempering" martensite). Fourth, when during the final transformation of the retained austenite in the structure of carbideless beinite with the formation of $\alpha$-iron and cementite particles. Fifth, in the implementation of the diffusion mechanism of $\gamma \Rightarrow \alpha$ transformation under the conditions of high degree of deformation and high temperature treatment.

Fig. 7 shows electron microscopy images of the pearlite colony, the cementite plates which are divided into separate fragments (the blocks). Sizes of fragments vary from 5 to 30 $\mathrm{nm}$. Simultaneously, cementite particles are found in ferritic interlayers of the pearlite colony, the sizes of whose particles vary from 5 to $10 \mathrm{~nm}$ (Fig. 7, the particles are indicated by arrows). Nanoscale range of the cementite structure of given pearlite colony is confirmed by quasicircular construction of the electron diffraction image derived from this plot foils (Fig. 7, d). Presented micrographs of the steel structure suggest that the thermomechanical processing is accompanied not only by mechanical destruction of the plates of cementite, but also their dissolution of with the departure of the carbon atoms on the dislocation and the subsequent precipitation in the body of ferrite plates.

Dispersion of the cementite plates may be accompanied by the formation of the block (subgrain) structure (Fig. 8). The newly evolved cementite particles in such a structure are located at block boundaries, stabilizing their sizes.

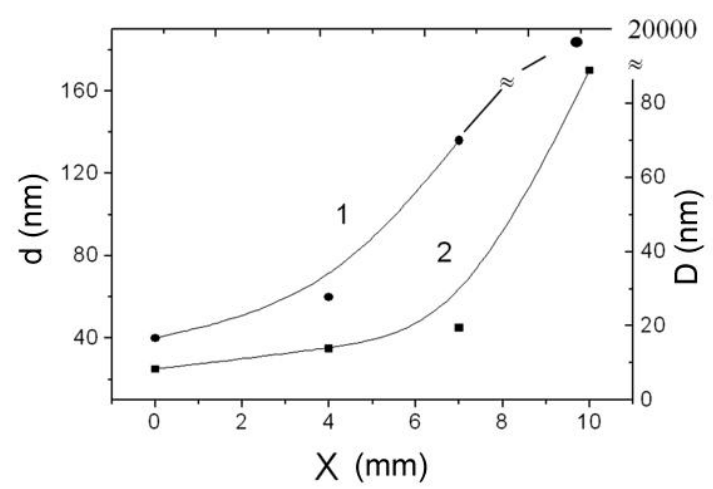

Fig. 6. Dependence from distance to surface midsized $\boldsymbol{d}$ fragments (particles) of cementite (curve 2) and midsized $\boldsymbol{D}$ fragments of ferrite (curve 1).
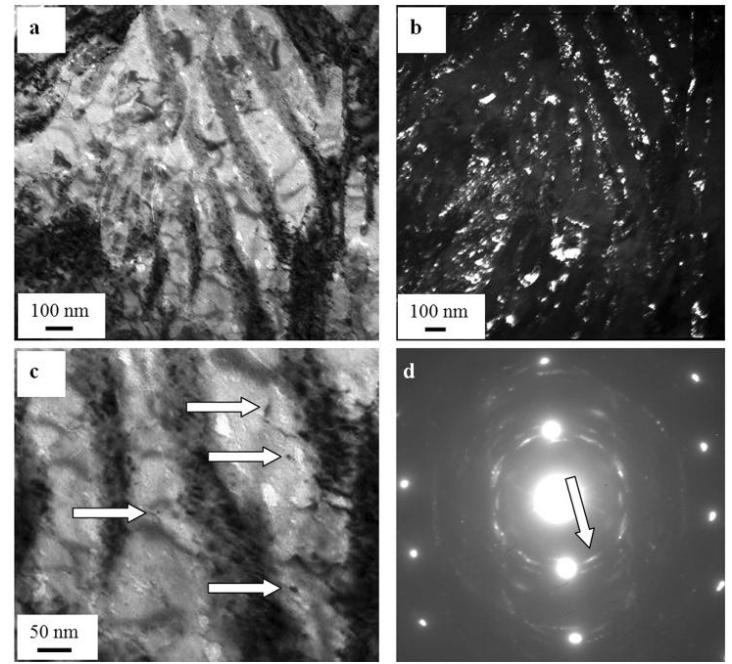

Fig. 7. The fragmentation of the cementite plates of perlite grains, a, c light-field image, $\mathrm{b}$ - dark field image obtained in the reflection [121] $\mathrm{Fe}_{3} \mathrm{C} ; \mathrm{d}$ - electron diffraction pattern image, the arrow indicates the reflection, in which a dark field image was obtained. On c) the arrows indicate cementite particles located in the plates of ferrite.

Removal of carbon atoms from destructed particles of cementite is possible and even at much greater distances. Studies of the block (subgrain) structure of $\alpha$-iron grains by methods of dark-field analysis revealed the cementite particles in the body of the blocks on the dislocations and block boundaries (Fig. 9). Particles have a rounded shape, particle sizes vary from 5 to $15 \mathrm{~nm}$.

Accelerated cooling of the H-beam leads to the formation of the martensitic structure in the surface layer. Subsequent "self-tempering" of the steel under the influence of the residual heat is accompanied by relaxation of the dislocation substructure, which manifests itself in reducing the scalar density of dislocations, the destruction of low-angle boundaries of martensite crystals, precipitation on dislocations within the body of martensite crystals (Fig. 10, a) and along the boundaries of cementite particles (Fig. 10, b). The sizes of particles located on dislocations, vary between $5 \ldots 10 \mathrm{~nm}$ (Fig. 10, a), located on the borders - in the $10 \ldots 30 \mathrm{~nm}$ range.

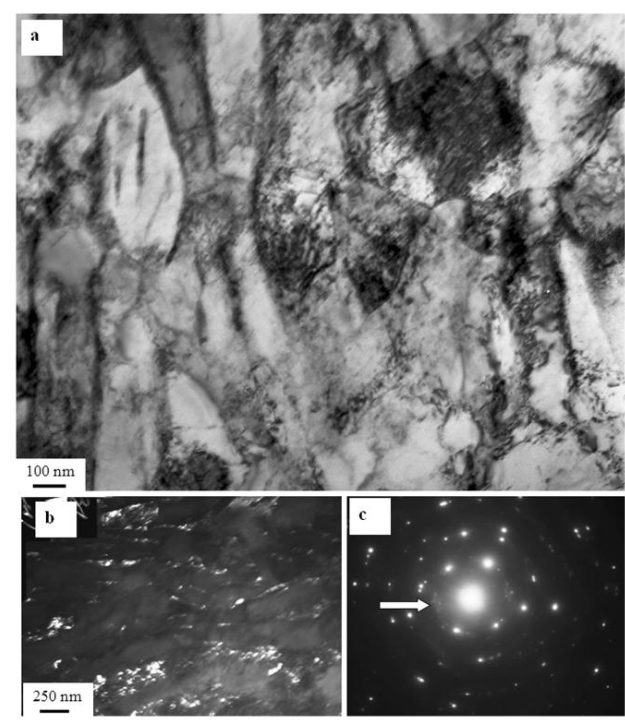

Fig. 8. The formation of a subgrain structure of the steel and fragmentation of the pearlitic grain cementite plates a - light-field image, $\mathrm{b}$ - dark field image obtained in the reflection [121] $\mathrm{Fe}_{3} \mathrm{C}$; c - electron diffraction pattern image, the arrow indicates the reflection, in which a dark field image was obtained. 


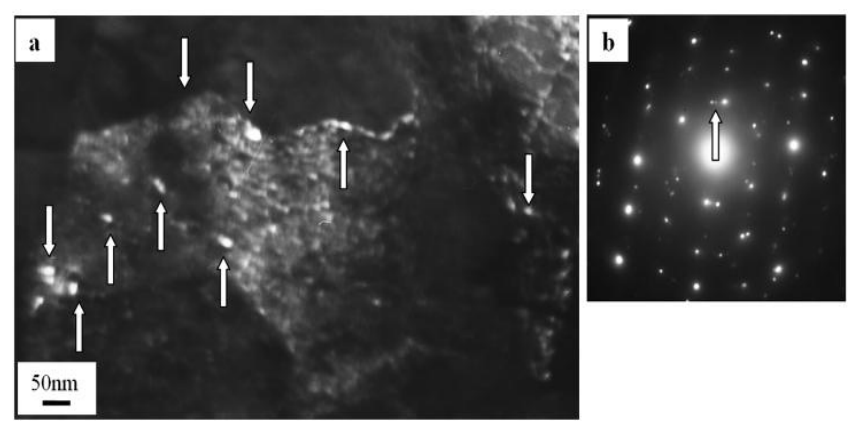

Fig. 9. Precipitations of second phase particles (cementite) within the body and at the boundaries of $\alpha$-phase subgrains: a - dark field image, obtained in the reflections [012] $\mathrm{Fe}_{3} \mathrm{C}+[110] \alpha-\mathrm{Fe}$ (particles indicated by arrows), $\mathrm{b}-$ electron diffraction pattern image, the arrow indicates the reflection, in which a dark field image was obtained.

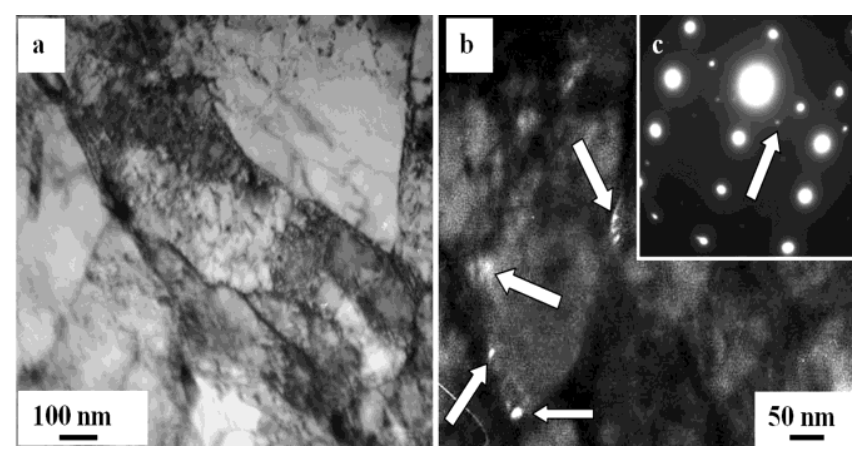

Fig. 10. The microstructure of the hardened layer of the H-beam, cooled by P1 regime, a - bright-field image, b - dark field image obtained in the reflection [120] $\mathrm{Fe}_{3} \mathrm{C}$; c - electron diffraction pattern image, the arrow indicates the reflection, in which a dark field image was obtained. On (b) the arrows indicate cementite particles.

In the surface layer of the steel sample cooled according to $\mathrm{P} 2$ regime, along with grain-subgrain structure the structure of plate type, the so-called carbideless bainite was observed. As shown above, the plates are arranged parallel to each other and there was an alternation of plates of light and dark contrast. Microdiffraction analysis of these structures revealed the presence of only the reflections of $\alpha$-phase. Reflections of the retained austenite and carbide phase particles are not detected. At the same time, mottled contrast reminiscent of the contrast from the pre-precipitates of second phase particles (Fig. 11) is revealed within the structure of the darker plates (formed, presumably as a result of the process of complete transformation of residual austenite)

The high level of steel plastic deformation, which is realized by thermomechanical processing of rolled products, leads to dispersion of structures formed in the process of diffusion of the $\gamma \Rightarrow \alpha$ transformation. Fig. 12 shows electron microscopy images of the structure of lamellar pearlite. The measurements show that the thickness of plates of $\alpha$-phase, separated by the plates of carbide, is about $70 \mathrm{~nm}$; the thickness of the plates of the carbide phase of $\sim 25 \mathrm{~nm}$.

Formation of nanosized particles of the carbide phase, is also observed in the formation of the so-called pseudoperlite, namely ferrite grains, containing particles of cementite of globular morphology (Fig. 13). The sizes of particles of cementite in these grains vary in the range $40 \ldots 60 \mathrm{~nm}$.

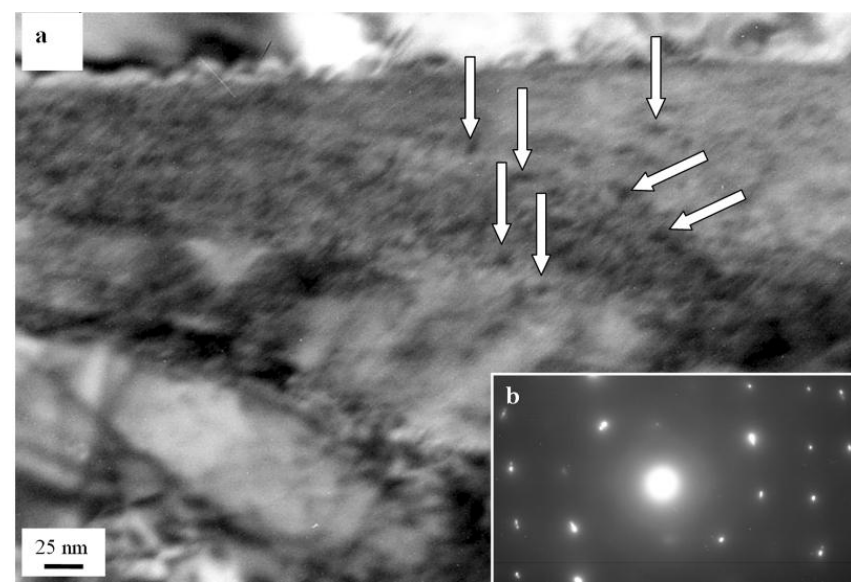

Fig. 11. Electron microscopic image of the structure formed at the transformation of the residual austenite; a - light field image, $b$ - electron diffraction pattern image of (a). Arrows indicate pre-precipitates of second phase particles.
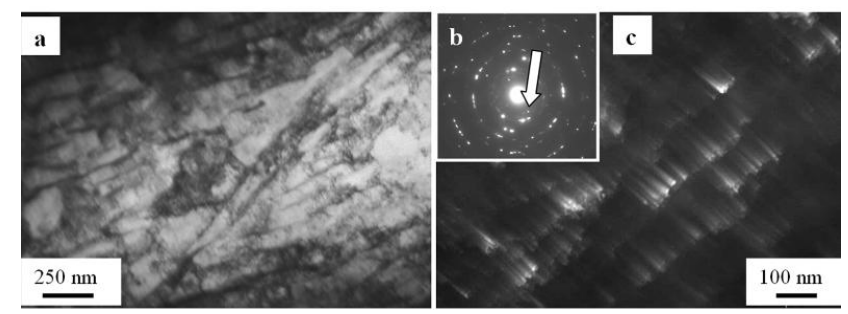

Fig. 12. Electron microscopic image of the structure of the lamellar (plate) perlite: $\mathrm{a}$ - light field image, $\mathrm{b}$ - dark field image obtained in [021] $\mathrm{Fe}_{3} \mathrm{C}$ the reflection; $\mathrm{c}$ - electron diffraction pattern image, the arrow indicates the reflection, in which a dark field image was obtained.
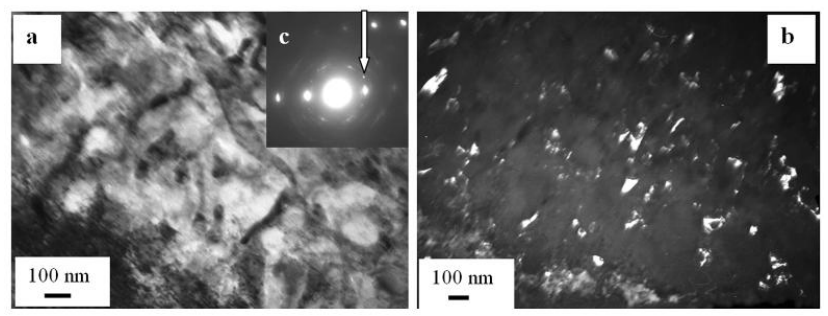

Fig. 13. Electron microscopic image of the pseudoperlite structure: a - light field image, $b$ - dark field image obtained in the reflection [012] $\mathrm{Fe}_{3} \mathrm{C} ; \mathrm{c}$ electron diffraction pattern image, the arrow indicates the reflection, in which a dark field image was obtained.

\section{CONCLUSION}

A study of the H-beam's structure phase states after thermomechanical strengthening was carried out using the methods of transmission diffraction electron microscopy.

The formation of gradient structure, characterized by regular changes of parameters of the structure-phase states and dislocation substructure as it approaches to the surface of the accelerated cooling was revealed. It was established that nanosize structure-phase states are formed in the surface layer.

The analysis of the processes leading to the formation of the structure within the beam profile of 09G2S steel nanoscale phases was carried out.

It is shown that the formation of nanoscale phases was carried out possibly in the implementation of the following processes. First, during dispersing of the cementite plates of pearlite colonies by cutting them by moving dislocations. 
Secondly, during the dissolution of pearlite colonies cementite plates and repeated precipitation of the cementite particles on the dislocations, the boundaries of blocks, subgrains and grains. Third, during the decay of solid solution of carbon in the $\alpha$-iron, formed under the conditions of accelerated cooling of steel ("self-tempering" of martensite). Fourth, during final transformation of the retained austenite in the structure of carbideless beinite with the formation of $\alpha$-particles of iron and cementite. Fifth, during the implementation of the diffusion mechanism of $\gamma$ $\Rightarrow \alpha$ transformation under the conditions of high degree of deformation and high temperature processing.

\section{REFERENCES}

[1] A. B. Yuriev, Thermomechanical strengthening of building bar, Science, Novosibirsk, 2006, pp. 423.

[2] O. Y. Efimov, "Structure-phase conditions and production technology of strengthened steel reinforcement and cast-iron rolls," Publishing house JCS Novokuznetsk printing plant, Novokuznetsk, 2008, pp. 300

[3] O. Y. Efimov, A. B. Yur'ev, Y. F. Ivanov, V. E. Gromov, and M. M. Morozov, "Thermomechanical hardening of large-diameter reinforcement," Steel in Translation, vol. 38, pp. 982-986, Dec. 2008.

[4] O. Yu. Efimov, Yu F. Ivanov, S. V. Konovalov and V. E. Gromov, "Gradient structural-phase states in the thermostrengthened low-carbon steel reinforcement," Materials and Manufacturing Processes, vol. 26, no. 1, pp. 144-146, 2011.

[5] V. E. Gromov, Y. F. Ivanov, V. B. Kosterev, S. V. Konovalov, V. I. Myasnikova, and G. Tang, "Formation of nanosize phases under thermomechanical strengthening of low carbon steel," in Proc. Intern. Conf. on Materials Engineering and Technology of WASET, Venice, 2011, pp. 2410-2412.

[6] V. E. Gromov, Y. F. Ivanov, V. B. Kosterev, and S. V. Konovalov, "Nanosize phases formation under low carbon steel thermomechanical strengthening," in Proc. 1th Intern. Conf. of Nanomaterials: Application and Properties (NAP 2011), Alushta, 2011, vol. 2, Part 2, pp. 293-301.

[7] P. B. Hirsch, A. Howie, R. B. Nicholson, D. W. Pashley, and M. J. Whelanet, Electron microscopy of thin crystals, Krieger Publishing Co., Melbourne, 1977.

[8] N. A. Koneva, E. V. Kozlov, Y. F. Ivanov, N. A. Popova, and A. N. Zhdanov, "Substructural and phase transformations during plastic deformations of materials obtained by intensive deformation," Material Science and Engineering A, vol. 410-411, pp. 341-344, 2005.

Victor E. Gromov is currently a Chief of Physics Department in the Siberian State Industrial University of Novokuznetsk (Russia). He received his PhD in Solid State Physics from the Laboratory of Strength Physics, Institute of
Physics Strength and Materials Science of Siberian Branch of Russian Academy of Sciences of Tomsk (Russia) and was appointed as Chief of Physics Department in 1992 and as Professor of Physics in 1992 at Siberian State Industrial University.

His main research interests are new processing technology, surface modification by electron and plasma beams, electroplastic deformation, fatigue and methods of its improvement by external energy influences.

$\mathrm{He}$ is a Member of Nanotechnological Society of Russia, member of Academy of Natural Sciences, Member of the International Academy of Energy Science. He is a Meritorious Science Worker of Russia (1998), Best Professor of Kuzbass region (2003), Russia Government Prize-Winner in the Field of Science and Technology (2005).

Yurii F. Ivanov is currently a Chief of Laboratory in the Institute of High Current Electronics Siberian State Industrial University of Siberian Branch of Russian Academy of Sciences of Tomsk (Russia). He received his PhD in Solid State Physics from the Laboratory of the Institute of High Current Electronics Siberian State Industrial University of Siberian Branch of Russian Academy of Sciences in 2002.

His main research interests are new processing technology, surface modification by electron and plasma beams, scanning and transmission electron diffraction microscopy.

Vadim B. Kosterev is an Engineer of JSC "EVRAZ-ZSMK" of Novokuznetsk. He obtained his $\mathrm{PhD}$ in Solid State Physics from the Laboratory of External Field Actions, Siberian State Industrial University in 2011. His research area is hot rolling process, and finite element simulation of rolling process.

Sergey V. Konovalov is currently an Assistant Professor in the Siberian State Industrial University of Novokuznetsk (Russia). He received his PhD in Solid State Physics from the Laboratory of External Field Actions, Siberian State Industrial University in 2002 and was appointed as Assistant Professor in 2003.

He is a Winner of the Governor's of Kemerovo region Award, Certificates of merit of Rector of Siberian State Industrial University, Mayor of Novokuznetsk, Governor of Kemerovo region.

His main research interests are new processing technology, surface modification by electron and plasma beams, electroplastic deformation, fatigue and methods of its improvement by external energy influences.

$\mathrm{He}$ is a Member of Nanotechnological Society of Russia and Senior member of the International Association of Computer Science and Information Technology.

Irina A. Komissarova is a Ph.D. student of Siberian State Industrial University in 2011.

She has Certificates of merit of Rector of Siberian State Industrial University.

Her main research interests are new processing technology, surface modification by electron and plasma beams, electroplastic deformation, fatigue and methods of its improvement by external energy influences. 